\title{
Viejas políticas y nuevos racismos. La izquierda frente a la islamofobia
}

\author{
Old politics and new racisms. The Left facing Islamophobia
}

Daniel GIL-BENUMEYA FLORES

Universidad Complutense de Madrid

daniel.gil@ucm.es

Recibido 16/4/2018. Revisado y aprobado para publicación 15/6/2018

Para citar este artículo: Daniel GIL-BENUMEYA FLORES (2018), “Viejas políticas y nuevos racismos. La izquierda frente a la islamofobia" en Revista de Estudios Internacionales Mediterráneos, 24, 49-70.

Para acceder a este artículo: https://doi.org/10.15366/reim2018.24.004

\section{Resumen}

Este artículo pretende acercarse a una comprensión de las posiciones de la izquierda europea y española sobre la islamofobia, así como de sus silencios, que contrastan con la centralidad que tiene la problematización del islam en otros segmentos del campo político y en las dinámicas de gobernanza global y local. Para ello, aborda en primer lugar la construcción de la cuestión musulmana en paralelo al auge del neoliberalismo, se pregunta por las dinámicas de poder que subyacen a la (re)producción de la islamofobia y finalmente propone un marco de análisis para las posiciones de la izquierda y una taxonomía de las mismas.

Palabras clave: islamofobia, islam, racismo, izquierda, política

\begin{abstract}
This article aims at understanding the positions of the European and Spanish left on Islamophobia, as well as its silences, which contrast with the centrality of the problematization of Islam in other segments of the political field and in the dynamics of global and local governance. To do so, it first addresses the construction of the Muslim question, in parallel with the rise of neoliberalism. Then, it considers the power dynamics that underlie the (re)production of Islamophobia and finally proposes a framework for the analysis, as well as a classification of the positions of the left.
\end{abstract}

Keywords: islamophobia, Islam, racism, left, politics 


\section{Introducción}

¿Cuál es la función política de la islamofobia? Son comparativamente pocos los estudios sobre la cuestión que investigan a fondo las conexiones de la islamofobia con estrategias políticas. Los enfoques estructurales se han centrado más en investigar cómo funciona el estigma que en por qué funciona, o, en otros términos, se ha hecho más hincapié en los imaginarios de la islamofobia que en su función sistémica y los actores sociales que la (re)producen y sus intereses (Kundnani, 2017: 73).

A ello se añaden las dificultades para delimitar la naturaleza de la islamofobia que, como se ve en la introducción de este monográfico, se manifestaron ya tempranamente en la definición múltiple del Runnymede Trust (1997). La islamofobia es, a la vez, un hecho global y local que articula un discurso geopolítico internacional con la gestión de las minorías musulmanas en el interior de los Estados. En la mayoría de las sociedades europeas, la islamofobia sucede y se solapa con la xenofobia, dirigidas una y otra contra las mismas personas, primero por su origen geográfico y sucesivamente por su «cultura» y su «religión» reales o supuestas. Por esa razón se ha propuesto hablar de musulmanofobia o racismo antimusulmán (Halliday, 1999: 898) entendiendo que sus víctimas son las personas "leídas como» musulmanas y no la religión en sí. Sin embargo, ese racismo antimusulmán es difícilmente disociable del cuestionamiento de la legitimidad del islam como fe y práctica religiosa y cultural y sobre todo de la legitimidad de su práctica en las sociedades del Norte.

El concepto de racialización soluciona analíticamente la filiación de la islamofobia con el racismo, en la medida en que considera que la raza no es una propiedad genética sino una ficción creada para naturalizar una relación de dominación. Eso permite aplicar a la islamofobia todo el corpus analítico producido sobre el racismo, incluido el que señala su carácter estructural en el Estado moderno, como dispositivo ${ }^{1}$ que justifica la colonización, la división del trabajo y los mecanismos de inclusión y exclusión inherentes a la formación de los Estados nacionales. Sin embargo, más allá de ese marco general, la identificación de islamofobia y racismo no explica por sí sola qué agentes la (re)producen y en función de qué intereses específicos (Massoumi et al., 2017a; Kundnani, 2017). La constatación de que existen quienes se benefician de ella no explica el papel sistémico de la islamofobia. Al contrario, la inconcreción parece sugerir que los actores políticos no hacen más que aprovechar, instrumentalizándolo y magnificándolo, un problema generado espontáneamente por el encuentro traumático entre Occidente y el islam (Göle, 2007 [2005]: 19). Sin embargo, ningún hecho social constituye per se un problema público, ni siquiera el hecho de que produzca un cambio objetivo en el ámbito de la vida social al que se refiere. La condición de posibilidad de un problema público es que sea construido como tal y aceptado socialmente a costa de otros potenciales problemas, para lo cual tienen que existir, entre otras cosas, unos agentes sociales que lo construyen y reproducen (Lorenc, 2005: 142-146; Hajjat y Mohammed, 2016: 102).

La islamofobia fue denunciada y nombrada como tal a mediados de los años noventa, pero deriva genealógicamente de un proceso más largo al que llamaré "cuestión musulmana» y que voy a reseñar brevemente. A continuación intentaré una caracterización política del problema y sus agentes para abordar por último los vínculos entre racismo, islamofobia e izquierda. Para el

\footnotetext{
${ }^{1}$ Dispositivo en sentido foucaultiano, es decir, red que integra instituciones, discursos, leyes, medidas administrativas, enunciados científicos, proposiciones ideológicas, filosóficas, morales, etc.
} 
análisis he tenido en cuenta sobre todo el marco que proporcionan las experiencias del Reino Unido y Francia señalando, cuando es necesario, las especificidades del caso español. No me ha parecido útil circunscribirme a este último, ya que la cuestión musulmana emerge en España tardíamente y, en gran medida, ya construida desde los países centrales del espacio europeo. Por otra parte, la convergencia comunitaria y la caracterización pospolítica del problema ha tendido a unificar su gestión y las percepciones sociales del mismo, pese a la diversidad de situaciones de partida (Rea, 2006: 161-167; Tyrer, 2013: 88).

\section{La construcción de la «cuestión musulmana»}

La "cuestión musulmana» se inicia en las postrimerías de los «treinta años dorados» del capitalismo, las décadas de desarrollo industrial y económico que siguieron a la segunda guerra mundial en los países del Norte global. Como se ha señalado, la cuestión tiene una dimensión internacional y otra doméstica. Edward Said denunció tempranamente en Orientalismo (1990 [1978]: 337) que los discursos antisemitas de preguerra se estaban transfiriendo de los judíos a los árabes. Una razón era la emergencia de la resistencia palestina después de 1967 que dio forma al «terrorismo árabe» en escenarios "occidentales» cada vez más decantados hacia Israel (Kapitan, 1997: 30, Finkelstein, 2002 [2000]). La segunda razón fue la crisis del petróleo de 1973 que propició una larga serie de representaciones sobre el «peligro árabe» (Said, 1990 [1978]: 337-338). Más tarde, la Revolución iraní de 1979 supuso un hito fundamental en la construcción del «mal» terrorista racializado (Kumar, 2017: 61) y favoreció la decantación de la amalgama árabe-islámica hacia el segundo elemento. La emergencia del islamismo político y su correlato cultural, el revivalismo islámico o "nuevo pietismo» (Göle, 2007 [2005]: 127) generaron importantes contradicciones en las izquierdas del Norte. Si bien la «nueva izquierda» y la "extrema izquierda» surgidas en los sesenta y setenta tenían un poso anticolonial y habían tendido a simpatizar (e incluso colaborar) con las organizaciones antiimperialistas del mundo árabe e islámico (Río, 2012: 17-18) la entrada en escena del islamismo político cambió las tornas. ¿Era el islam un mero «lenguaje» anticolonial superpuesto a unas luchas de liberación cuya esencia permanecía inmutable o debía entenderse como una «doctrina» a todos los efectos y por tanto tomar nota de sus incompatibilidades con la izquierda laica? Ese es, presentado con trazo grueso, uno de los debates inacabados de la izquierda en su relación con el islam.

Al colapso del bloque socialista a partir de 1989 siguió la reafirmación de la hegemonía estadounidense que estaba en crisis desde mediados de los setenta. La devastación de Iraq (19901991) fue el acontecimiento inaugural de un «nuevo orden mundial» definido por el «choque de civilizaciones» y la emergencia de una nueva amenaza islámica global que cristalizaría tras el 11-S y la «guerra contra el terror». La islamofobia surge como ideología imperial (Kundnani, 2017; Kumar, 2017) que funciona gracias a que concuerda, por una parte, con el racismo estructural de la Modernidad colonial europea y por otro con un repertorio antiislámico de largo recorrido.

La dimensión interior del problema musulmán aparece con la revolución neoliberal. El desmantelamiento del pleno empleo y el Estado del bienestar derivó tempranamente en una estigmatización de la mano de obra no cualificada de origen inmigrante, importada masivamente durante las décadas anteriores, y especialmente aquella que procedía de las colonias y excolonias 
europeas. La problematización de la inmigración no detuvo la afluencia de migrantes probablemente no lo pretendía - pero sí creó un estigma funcional a la reorganización productiva y social que por un lado precarizaba y por tanto abarata la mano de obra - tanto la inmigrante como la autóctona, obligada a competir con ella- y por otro creaba un chivo expiatorio adecuado a las esperanzas frustradas de la clase obrera nativa. El neoliberalismo popularizó discursos xenófobos que hasta entonces habían sido patrimonio de sectores ultraconservadores y ultraderechistas, transformándolos en un activo, no ya político sino pospolítico, en la medida en que se presentaban como una cuestión de "gestión eficiente», transversal o ajena a las ideologías políticas. En ese contexto, se produjeron las primeras conexiones entre el «problema de la inmigración» local y el «problema musulmán» global, esencialmente como un medio de desacreditar las reivindicaciones de la clase obrera inmigrante y de crear un estigma culturalista, que escapara a las definiciones de racismo generalmente admitidas (Hajjat y Mohammed, 2016: 105-106). Los "asuntos del velo" en Francia y el caso Rushdie en el Reino Unido (1989) fueron los que consolidaron la percepción de un «problema musulmán» global y local a la vez, que cristalizó una década más tarde con el 11-S y la aparición del «terrorismo islámico» en Europa².

La revolución neoliberal supuso también un importante cambio en las izquierdas. El desmantelamiento de la fábrica como espacio hegemónico de la producción, pero también del antagonismo de clase, hizo que la izquierda obrerista asistiera a la lenta reducción de su base social y su capacidad de acción, desbordada por los nuevos patrones de trabajo, interacción social y control biopolítico, en los que resultaba cada vez más difícil orientarse. Las izquierdas ni siquiera pudieron rentabilizar la "crítica cultural» de la nueva izquierda, sensible a los factores deshumanizadores de la producción en masa de los "años dorados», ya que en gran medida el capital se apropió de ella para transformarla en instrumento de reestructuración (la indistinción entre lugar y tiempo de vida y de trabajo, la movilidad laboral y la formación permanentes, los nuevos modelos empresariales, etc.). En cuanto a la inmigración, las izquierdas ya habían tenido dificultades para integrar en sus estructuras a los trabajadores inmigrantes no cualificados (Pitti, 2004; Brah, 2011 [1996]: 53; Keucheyan, 2013 [2010]: 115) y el problema se hacía más agudo ahora debido a su percepción como competidores de la clase obrera local. Por otro lado, si bien las izquierdas se mostraban sensibles al racismo, los nuevos racismos culturalistas y la islamofobia provocaron en su seno contradicciones similares a las que había propiciado el auge del islamismo a nivel global.

\footnotetext{
${ }^{2}$ El caso español fue algo distinto. España recogió a finales de los ochenta la inmigración excedente de Europa, que creció en paralelo a la burbuja inmobiliaria, en un proceso cuya intensidad y rapidez no se había dado en ningún otro país de la UE (González Enríquez, 2017: 3-5). La Ley de Extranjería de 1985 ya discriminaba a los musulmanes incluidos los habitantes de Ceuta y Melilla - en el acceso a la nacionalidad, por lo que desde los inicios funcionó un "filtro étnico», más alimentado por la morofobia que por el rechazo al islam (López García, 2002: 130-137). Los sucesos de El Ejido en febrero de 2000 marcaron el gran punto de inflexión de la problematización de la inmigración, todavía no de la musulmaneidad. La amenaza específicamente musulmana se construyó sobre el llamado «terrorismo islámico». Aunque España ya había sido escenario, en 1985, de uno de los primeros atentados atribuidos al "yihadismo», el problema no se planteó hasta dos décadas más tarde, ya en la estela del 11-S, con los atentados del 11 de marzo de 2004 en Madrid y los del 17 de agosto de 2017 en Barcelona (con relación a estos últimos, remito al artículo de Alberto López Bargados en este mismo número).
} 


\section{La islamofobia y sus agentes}

La islamofobia ha sido identificada como una forma de caza de brujas (Kumar, 2017: 61). Más allá del uso figurado de la expresión, la caza de brujas propiamente dicha, que recorrió Europa y sus colonias en los albores de la Edad Moderna, fue analizada por Silvia Federici como un mecanismo de disciplinamiento de poblaciones ligado a la reorganización social y productiva del primer capitalismo y en particular a la acumulación primitiva de fuerza de trabajo. Federici señala (2010 [2004]: 24) que «cada fase de la globalización capitalista, incluida la actual, ha venido acompañada de un retorno a los aspectos más violentos de la acumulación primitiva». En esta línea, podemos entender que la islamofobia es una forma de racismo ligada a las nuevas reconfiguraciones del capitalismo. La destrucción de Iraq, el desplazamiento masivo de poblaciones a través de los conflictos o la privatización de los servicios públicos (cuyo déficit se achaca entre otras cosas a la sobreexplotación por parte de los inmigrantes) son otras tantas formas de lo que David Harvey (2004 [2003]) ha llamado «acumulación por desposesión». Esto es, una captura violenta del bien común que tiene por objeto reiterar periódicamente la acumulación primitiva a fin de reimpulsar el rendimiento del capital. Por otra parte, el 11-S y la "guerra contra el terrorismo" constituyen el punto de inflexión hacia lo que Giorgio Agamben (2004 [2003]: 25) ha llamado un estado de emergencia o de excepción permanente como paradigma de gobierno. Guantánamo es el icono temprano de esa excepcionalidad ligada a la gestión de la «amenaza terrorista» y la construcción de los musulmanes como "categoría punible de personas» más allá del derecho (López Bargados, 2015: 27). La islamofobia no es pues (o no únicamente) una discriminación religiosa sino "una expresión emblemática del racismo biopolítico contemporáneo» (Tyrer, 2013: 21), cuyo leitmotiv es la religión pero que se nutre, además, de otros resortes de alterización e inferiorización como la xenofobia, el clasismo, el sexismo o la peligrosidad.

¿Quiénes producen y reproducen la islamofobia? Partiendo de la identificación propuesta por Massoumi et al. (2017a), nombraré a tres agentes sociales ${ }^{3}$. En primer lugar, lo que vagamente podríamos llamar "ultraderecha» - enseguida matizaré la idea-, de la que procede el grueso del discurso islamófobo explícito. En segundo lugar, las instituciones estatales, agente medular del racismo y no mero instrumento, cuyo papel sin embargo solo se esbozará ya que lo contrario excedería los propósitos de este trabajo. $Y$, por último, me referiré a un sector de la izquierda; en la sección siguiente se propondrá una taxonomía de posiciones de izquierda sobre la islamofobia y se mostrará cómo existen sectores y discursos dentro de la misma que intervienen de manera activa en la producción del estigma antimusulmán.

La «ultraderecha» en un sentido laxo está conformada por al menos tres movimientos de élite con características distintas, aunque puedan darse combinaciones y desplazamientos. En primer lugar, el movimiento neoconservador, que proporcionó el apoyo ideológico al giro beligerante emprendido por la política exterior de Estados Unidos a partir de mediados de los años noventa y

\footnotetext{
3 Massoumi et al. (2017a) hablan en realidad de "cinco pilares» de la islamofobia: 1) el Estado; 2) partes del movimiento sionista; 3) el movimiento neoconservador; 4) el movimiento counterjihad y la extrema derecha; y 5) diversas corrientes de izquierda, progresistas y feministas. En este artículo se contemplan todos, pero he optado por una reducción a tres bloques.
} 
del que procede gran parte de la expertise sobre la "amenaza islámica» ${ }^{4}$. En segundo lugar, la ultraderecha propiamente dicha: los movimientos de raíz fascista y racista, generalmente homófobos y sexistas, abonados a la estigmatización y, frecuentemente, la violencia directa contra toda clase de minorías, y que a menudo hacen bandera del antisemitismo del fascismo histórico ${ }^{5}$. $Y$ en tercer lugar, el fenómeno emergente del llamado "extremismo de centro», "nuevo fascismo» o "populismo de derechas», entre otras denominaciones, que aquí llamaré posfascismo siguiendo a Tamás $(2000,2015)$ y Traverso $(2015,2016)$.

En los países de Europa occidental, esa modalidad de ultraderecha ascendente que ha sido calificada provisionalmente como posfascismo tiene importantes diferencias con el fascismo clásico, del que en ocasiones procede y otras veces no. En primer lugar, se preocupa en marcar distancias con todo aquello que pueda ser identificado como ultraderechista ${ }^{6}$. En segundo lugar, no es totalitario ni revolucionario: no se opone a las formas políticas dominantes de democracia electoral y gobierno representativo, y con frecuencia hace bandera de los derechos individuales, incluida la igualdad de género y la libertad sexual. No es en absoluto antisemita; todo lo contrario: comparte con los neocon su afinidad con el sionismo y la transformación del Holocausto en una nueva «religión civil» (Traverso, 2016: 113-127). No se basa «en movimientos de masas violentos y filosofías irracionales y voluntaristas» (Tamás, 2000) y de hecho no está respaldado, al contrario que el fascismo clásico, por ninguna producción teórica reseñable, aunque sí cuente con hitos literarios de gran circulación como La rabia y el orgullo de Oriana Fallaci (2001) o Sumisión de Michel Houellebecq (2015), por citar un texto fundacional y otro reciente. El posfascismo carece de autodefinición política clara; de hecho, se trata de un movimiento netamente pospolítico y populista, que se presenta como ajeno o transversal a las ideologías y que reivindica el retorno de la «gente común» a la «normalidad» perdida por las transformaciones sociales de las últimas décadas, en particular el multiculturalismo. ${ }^{7}$ El posfascismo disputa la hegemonía a la izquierda no solo en sus mismos espacios y segmentos sociales, sino también con sus mismos moldes discursivos e icónicos (Reguera, 2017). En la mayoría de los casos puede decirse que lo ha hecho exitosamente. ¿Qué justifica entonces su asimilación a la extrema derecha? Para Tamás (2010), la

\footnotetext{
${ }^{4}$ El espacio neocon está representado sobre todo por think-tanks y grupos de presión como la Henry Jackson Society en el Reino Unido, Counterjihad Europa o European Fundation for Democracy, entre otros. En España, el espacio neocon lo dominan el Grupo de Estudios Estratégicos (GEES), la Fundación para el Análisis y los Estudios Sociales (FAES), la Fundación Burke y quizás la Fundación Juan de Mariana - a la que otros identifican más bien con lo que en el ámbito anglosajón se denomina libertarianism - , así como algunos medios de comunicación como Libertad Digital e Intereconomía (Carmona et al., 2012).

${ }^{5}$ Un problema para determinar quiénes se adhieren a esta categoría es que gran parte de las grandes organizaciones europeas de ultraderecha - como el FN francés, el Partido de la Libertad de Austria (FPÖ) o el Vlaams Belang (heredero del Vlaams Blok, flamenco) - se han deslizado hacia posiciones más afines a las del posfascismo. Las organizaciones que responden más netamente a la tipología (neo)fascista serían Amanecer Dorado en Grecia, Casa Pound en Italia, Ley y Justicia en Polonia o el Movimiento por una Hungría Mejor. En España, el espacio fascista lo representan organizaciones como el Movimiento Social Republicano, España 2000 o la Falange, y experiencias de nuevo cuño como el madrileño Hogar Social, inspirado en el movimiento de centros sociales okupados. Pero por razones diversas (Casals Meseguer, 2017 y González Enríquez, 2017), no han prosperado los intentos de dotar a la ultraderecha constituida como tal de una base social amplia, ni siquiera con desplazamientos posfascistas (como los amagados por formaciones como España 2000, Plataforma per Catalunya o Vox).

${ }^{6}$ El recambio generacional en el FN sería el ejemplo más claro de esa distancia. Pero hay formaciones sin pasado fascista como el Partido por la Libertad (Partij Voor de Vrijheid, PVV) de Geert Wilders o los círculos de Pim Fortuyn o Donald Trump. En España, aunque existen organizaciones que pretenden trascender los marcos clásicos de la ultraderecha, el grueso del discurso posfascista se expresa por el momento a través de medios de comunicación y personalidades integradas en diversas formaciones políticas.

${ }^{7}$ En este aspecto, coincide con el análisis neocon del "peligro islámico», cuando se expresa no en nombre de valores ideológicos sino en términos de gobernanza.
} 
principal característica compartida entre fascismo y posfascismo es que urevierten la tendencia de la Ilustración de asimilar la ciudadanía a la condición humana» y restituyen al Estado soberano la capacidad de decidir discrecionalmente quién puede y quién no pertenecer a la comunidad cívica, y por tanto quién es objeto de derechos y quién no. Si bien podemos objetar que esa distinción está implícita en la llustración (piénsese en las colonias, por ejemplo), y de hecho fue teorizada por Ernst Fraenkel (1941) bajo la denominación de Estado dual, el discurso del posfascismo instituye y explicita la idoneidad de un poder formado por dos ámbitos: uno normativo, donde la actividad estatal está sujeta a una reglamentación jurídica y fiscalizada por un poder judicial independiente, y otro discrecional, donde el poder actúa permanentemente como en un estado de excepción y el derecho positivo es anulado o supeditado a las necesidades de la situación excepcional. Recrea el poder sacro premoderno, que se ejercía de manera heterogénea o asimétrica, e incide en la facultad del soberano para decidir en todo momento cómo y a quiénes se aplica un régimen $u$ otro, lo que en sí constituye una discrecionalidad permanente. Al contrario que en el fascismo clásico, totalitario, el Estado discrecional solo es vagamente visible para los ciudadanos del Estado normativo, que en el Norte global constituyen la mayoría de las poblaciones. Por otro lado, la racialización-extranjerización del otro facilita su exclusión de la ciudadanía, dentro de la lógica implícita en el Estado nación. Es un «capitalismo sin rostro humano» (Traverso, 2017: 17).

El discurso posfascista goza de un predicamento que va mucho más allá de los agentes que lo producen. La discrecionalidad soberana que el posfascismo reclama existe de hecho: la gestión de las fronteras, los Centros de Internamiento de Extranjeros, el acoso policial, los programas de lucha antiterrorista o de denuncia y prevención de la «radicalización», así como la frecuente unidireccionalidad de las consideraciones laicistas, marcan a determinados segmentos de la población como personas sujetas a la excepcionalidad, en función de características raciales no explicitadas normativamente pero no menos operativas. Cuando la aplicación de esa discrecionalidad rebasa el ámbito del Estado y se hace extensible a la sociedad - pensemos en violencias y arbitrariedades cometidas contra musulmanes (y más habitualmente, musulmanas) en el espacio público, con razones y normas improvisadas - viene a la mente la figura del homo sacer, la persona desprovista de ciudadanía, reducida a nuda vida, "con respecto al cual todos los hombres actúan como soberanos» (Agamben, 2003 [1995], 110).

Lo anterior lleva entonces a considerar que el mayor agente de la islamofobia y a la vez el menos nombrado, su "columna vertebral» (Massoumi et al., 2017a: 8 y ss.), lo constituyen las instituciones estatales. El racismo, en efecto, no es una colección de prejuicios sino ante todo una relación de poder institucionalizada, que requiere una violencia legalmente autorizada, una rutina burocrática y una deshumanización de las víctimas como objetos de la burocracia, que no podría darse sin el concurso de los aparatos ideológicos del Estado (Bauman, 1998 [1977]: 27, 87-88, 133136). Aunque los poderes públicos no formen un bloque homogéneo sin fisuras ni contradicciones, resulta complicado ver en ellos una instancia arbitral y mediadora en materia de racismo salvo que se reduzca el racismo a un problema de "tolerancia» en las relaciones interpersonales, que es el enfoque que adoptan, necesariamente, las iniciativas «antirracistas» institucionales. 


\section{Islamofobia e izquierda}

La indefinición de la izquierda respecto a la cuestión musulmana contrasta con la centralidad del tema en otros puntos del campo político y lleva a interpretaciones opuestas. La acusación de islamoizquierdismo-que recuerda al judeobolchevismo de otros tiempos- sugiere una complicidad de la izquierda con los sectores más reaccionarios del islam. Otros achacan el silencio de la izquierda a su matriz colonial y a que considera el racismo como mero derivado superestructural de las relaciones de clase (Garcés, 2017). Se ha señalado también a determinados sectores de la izquierda y del "progresismo" como uno de los agentes fundamentales de la producción del discurso islamófobo (Massoumi et al., 2017b). ¿Se pueden extraer conclusiones generales? Sin adentrarnos en la complejidad que subyace al significante izquierda, las tomas de posición sobre la cuestión musulmana, cuando existen, ponen de manifiesto aproximaciones antagónicas, que no se corresponden con las segmentaciones ideológicas y que a menudo responden a estrategias que tienen poco que ver con el discurso que se explicita (Lévy, 2010: 30).

Si bien el antirracismo no ha sido una lucha central de la izquierda, también es cierto que ha sido una de sus luchas recurrentes ${ }^{8}$. De hecho, dentro de la abundante literatura sobre el fracaso de la izquierda, se señalan con insistencia sus derivas "culturalistas» y su abandono de la clase obrera blanca en favor de las «minorías». Volveré sobre ello. Dejando aparte la instrumentalización del antirracismo por fenómenos como SOS-Racisme (Juhem, 1998), han existido numerosas experiencias interseccionales en el terreno de los movimientos y centros sociales, sin duda minoritarias pero no planteadas necesariamente en términos «morales» más o menos bienintencionados ${ }^{9}$, sino desde un cuestionamiento de los fundamentos de la nacionalidad, la ciudadanía y el racismo (Suárez-Navaz et al., 2007).

Por tanto, más que referirse a características esenciales quizás sería útil analizar las distintas apuestas políticas en términos de adquisición o pérdida de capital (Bourdieu y Wacquant, 1995: 63-76). Un esquema posible sería considerar que el capital por el que compite la izquierda en el campo político se estructura en torno a dos ejes. El primero refleja la tensión entre la producción de efectos sociales, es decir, la capacidad de incidencia social, y la reproducción de la izquierda como espacio de legitimidad e identidad. La tensión radica en que el lado de la producción implicaría una mayor adecuación de los mensajes a los imaginarios sociales mayoritarios, aun a costa de una rebaja de las formulaciones ideológicas explícitas, que serían en cambio celosamente guardadas por el lado de la reproducción. El segundo eje, siguiendo la diferenciación propuesta por Chantal Mouffe (2007: 16-17), se arbitraría entre la política, esto es, la esfera institucional y por tanto la competencia por la gestión de las instituciones, y lo político, que remite a los antagonismos sociales y por tanto a cuestiones de legitimidad y luchas simbólicas sobre los principios de visión y división del mundo. ¿Cómo se inserta en este marco la cuestión del racismo? Con seguridad, una mayoría social considera reprobable la discriminación "por el color de piel», por lo que los agentes que aspiren a adquirir capital en el extremo de lo productivo tendrán que

\footnotetext{
${ }^{8}$ Según Dancygier $(2017: 83-85,96)$, los asuntos relativos a la no discriminación de personas de origen migrante o los derechos de migrantes y refugiados ocupan entre un 8 y un $17 \%$ de los discursos públicos de la izquierda europea (Bélgica, Reino Unido, Austria y Alemania), mientras que no llegan a un $1 \%$ en el caso de la derecha. A la inversa, las representaciones negativas de migrantes y refugiados ocupan entre un 14 y un $17 \%$ de los discursos de derechas y entre un 1 y un $2 \%$ de los de izquierdas. Los partidos de izquierdas tienen también una representación considerablemente mayor de candidatos musulmanes.

9 Así se denunciaba recientemente en un debate monográfico sobre fascismo y racismo en Radio Vallekas (La Contraparte, 2018).
} 
marcar distancias con el racismo en su acepción más común. No ocurre lo mismo con lo relativo a la inmigración, que remite a una regulación legal -distinción nacionales/extranjeros, legales/ilegales... - coherente con la lógica del Estado nación que las propias izquierdas, con escasas excepciones, aceptan como marco político. Por ese motivo, la solidaridad con migrantes o desplazados, particularmente cuando se juega en el terreno de la producción y de la política, se basa más en una apelación a lo humanitario ${ }^{10}$ que en una crítica a los modelos de ciudadanía y circulación de personas. Por otro lado, la culturalización del racismo genera algunas distorsiones: discriminar por el origen "étnico» (o el sexo) se considera más grave que discriminar por las prácticas culturales, pues se entiende que lo primero es innato y lo segundo es de naturaleza adquisitiva: puede que sea heredado, pero en última instancia mantenerlo o revertirlo es una elección. Cuando, como ocurre a menudo con el islam, la práctica cultural cuestionada se presenta como ilegítima desde una óptica laica (es una religión), securitaria (es peligrosa), nacionalista (es extraña), progresista (es retrógrada), antisexista (oprime a las mujeres), etc. (Hajjat y Mohammed, 2016: 200-203), el antirracismo debe sortear aquellos aspectos de la racialización que le resultan incómodos. En estas circunstancias, el antirracismo solo puede ser funcional en términos de adquisición de capital a costa de determinadas disecciones, en las que se aísla por ejemplo lo "étnico», más asumible, de la discriminación legal o de la estigmatización culturalista. De modo que sea posible solidarizarse con alguien en tanto que "negro» o "extranjero» sin necesidad de cuestionar su estatuto de «no ciudadano» o reivindicar su libertad religiosa, por ejemplo. ${ }^{11}$ Naturalmente, esto implica construir unos referentes ideales, que no se corresponden con una realidad en la que los distintos resortes de alterización se presentan entrelazados. Pero esta construcción es posible porque esa realidad es en el fondo poco relevante para el juego: su papel es simbólico. Por ese motivo, ocurre que dos valores conceptuados de izquierdas como el multiculturalismo y el laicismo se conjuguen por ejemplo en un antirracismo islamófobo. Este es sin duda contradictorio respecto al colectivo social de referencia, pero puede resultar coherente cuando lo que se pretende no es tanto producir un antirracismo con efectos reales sino enarbolarlo como representación simbólica (Dancygier, 2017).

\footnotetext{
10 Lo humanitario como ámbito separado de lo político, dice Agamben (2003 [1995]: 169) es «la fase extrema de la escisión entre los derechos del hombre y los derechos del ciudadano». Las acciones humanitarias, por definición, tratan a las personas objeto de su solidaridad como nuda vida y no como sujetos de derechos, por lo que «mantienen, a su pesar, una secreta solidaridad con las fuerzas a las que tendrían que combatir».

${ }^{11}$ Un ejemplo de todo esto lo hemos podido ver con las reacciones del entorno político del Ayuntamiento de Madrid a la muerte del mantero Mame Mbaye tras una persecución policial en marzo de 2018. Las manifestaciones de condolencia y solidaridad por su situación humanitaria (senegalés, inmigrante, precario) fueron asumidas por el equipo de gobierno al más alto nivel. La crítica específica al acoso policial al que se somete a los vendedores ambulantes o al hecho de que Mbaye no tuviera residencia legal a pesar de llevar más de una década en España, cuestiones ambas que remiten al papel que cumplen determinadas disposiciones legales y prácticas institucionales en la producción de exclusión social, solamente se prodigaron en los sectores críticos del equipo municipal y su entorno político. La discriminación religiosa subyacente a la colecta organizada por sus compañeros para la repatriación del cadáver no parece haber sido objeto de comentario. Hay que recordar que, más allá de las preferencias personales y familiares, el hecho de que la mayoría de los musulmanes fallecidos en Madrid sean enterrados fuera, pese a los costes, se debe a la ausencia de un cementerio islámico en la capital (promesa hasta la fecha incumplida por el equipo municipal) y a la extendida hostilidad de las administraciones hacia los enterramientos islámicos (Gil-Benumeya, 2016). Ni siquiera Esteban Ibarra, presidente del Movimiento contra la Intolerancia, que señalaba que Mbaye era "sufí, la rama del Islam más parecida a Ghandi [sic], pacifista» (Europa Press, 2018) establecía la relación entre una cosa y otra.
} 
Así, no es infrecuente la representación de colectivos racializados en la izquierda, incluidos los musulmanes, ya sea a través de personas que ocupan puestos visibles (aunque pocas veces dirigentes) en las organizaciones o en las candidaturas, o que actúan en diversos foros como interlocutores o referentes «autorizados» - es decir, a los que el propio universo cultural de la izquierda otorga un marchamo de autoridad-. También puede tratarse de una representación meramente iconográfica. Sin embargo, esta inclusión no pretende interpelar a los sectores sociales racializados como agentes de cambio social sino simbolizar el carácter antirracista, cosmopolita y abierto de la izquierda de cara a su base social, electoral y militante de clase media «blanca». De hecho, Dancygier (2017: 31-32; 2018) afirma que esa representación simbólica, que en el caso de los musulmanes es muy frecuentemente encarnada por mujeres, es tanto más habitual cuanto menos importante es, en términos políticos (y electorales), el segmento social representado. Por esa razón, es irrelevante que esa representación se ajuste a la realidad social que pretende representar; basta con que coincida con los marcos sociales y simbólicos en los que se despliega la actividad de la izquierda.

Analizando, pues, el antirracismo en términos de adquisición o pérdida de capital político en el esquema arriba propuesto tenemos que, en el extremo de lo productivo, la mayoría social puede ser sensible a determinadas formas, instituidas, de antirracismo pero ello no impide que los dispositivos de discriminación institucionalizados y el racismo culturalista estén relativamente normalizados. Por otro lado, la masa social directamente concernida por el racismo es poco relevante en términos políticos y electorales (además de que nada hace presagiar un apoyo necesario a opciones de izquierda). ${ }^{12}$ En el extremo reproductivo, el antirracismo tiene cierto lugar simbólico como valor "de izquierdas", pero enfrenta diversas dificultades: a) los sujetos racializados son poco relevantes en la masa militante y la audiencia de las organizaciones de izquierdas; b) las mutaciones del racismo complejizan el debate antirracista -la tensión laicismo/islamofobia, por ejemplo-, que puede ser soslayado por excesivamente complejo y poco rentable; y c) el antirracismo parece tener la facultad de resucitar, reactivamente, la idea de la lucha de clases como verdadero terreno de la lucha de la izquierda en el que deben subsumirse los demás (Khiari, 2012 [2011]).

En efecto, la pérdida de terreno frente a los fascismos y posfascismos ha dado pie a un género autocrítico con el distanciamiento de la izquierda respecto a la clase obrera - o a la "gente»- y sus preocupaciones (Halimi, 2016a; Hernández, 2017a; Lenore, 2018; Bernabé, 2018). En parte, el auge de este discurso se debe a que la crisis iniciada hace ahora una década resituó en el debate la cuestión de la desigualdad material, que había quedado eclipsada por una cierta idea de autonomía de lo discursivo y lo político (Carretero, 2017). En este marco han surgido obras como la de Owen Jones (2012 [2011]), que reivindican la (re)centralidad de las relaciones de clase. Aunque este discurso no desconoce la importancia de "las nuevas demandas civiles de las minorías y del feminismo y ecologismo», sí señala que se han articulado "a costa de abandonar a los segmentos más desprotegidos de la clase trabajadora» (Garzón, 2016). Lo cual da paso al corolario que identifica a la clase obrera -o a la "gente»- con la clase obrera "blanca» (y masculina $)^{13}$ y señala de manera más o menos explícita, según los casos, el lastre que supone para

\footnotetext{
12 Dancygier (2017: 57-59) señala entre la población musulmana europea tendencias más conservadoras que la propia derecha en lo tocante a igualdad de género, derechos de los gais y religiosidad. Coincidirían globalmente con la izquierda en la necesidad de políticas redistributivas.

13 Según Dancygier (2017: 64-65), los originarios de países de mayoría musulmana en Europa globalmente tienen mayores índices de paro y peores salarios que sus conciudadanos de origen nativo. Sin embargo, la clase obrera
} 
la izquierda ocuparse de cuestiones que suponen poco significativas o incluso contrapuestas a las preocupaciones de la gente común, como la igualdad de género, la libertad sexual y, por encima de todo, la solidaridad con migrantes y minorías culturales (Romero y Tirado, 2016: 24, 220). El discurso sobre el aburguesamiento multiculturalista y feminista de la izquierda se recupera y amplifica con cada avance de la ultraderecha. Žižek (2016: 71), por ejemplo, reafirma el antagonismo de clase como sobredeterminante de todos los demás y señala que el feminismo y el antirracismo funcionan "como una herramienta ideológica de las clases medias altas para afirmar su superioridad sobre las clases bajas».

En el diagrama propuesto, la invocación de la clase tiene un indudable valor en el eje de la reproducción, porque remite a los orígenes mismos de la izquierda. En el eje de la producción, sin embargo, aunque la mayoría social pudiera encajar en la definición de clase, muy poca gente se reconoce en la misma, de ahí los diversos intentos de nombrar un nuevo sujeto político mayoritario - «el 99\%», "los de abajo», los que no pertenecen a "la casta», etc. - . Sin embargo, la izquierda suele carecer también en este caso de una masa activista vinculada a esa "clase» a la que se quiere interpelar. En efecto, el mismo discurso autocrítico reconoce el desplazamiento del perfil militante hacia la uniformidad de clase media (Hernández, 2017b; Dancygier, 2018). En palabras de César Rendueles, «En España apenas hay militantes de clase baja. Se pueden contar con los dedos de una mano. [...] La realidad son círculos muy reducidos, casi siempre de clase media, con alta cualificación académica y normalmente con alguna conexión familiar con el mundo de la izquierda tradicional», en un tejido asociativo que es, por lo demás, muy inferior a la media europea (cit. en Lenore, 2016) ${ }^{14}$. En esas circunstancias, no es extraño que la invocación de la clase parezca más una ceremonia de autoafirmación que una categoría analítica y operativa real (Khiari, 2012 [2011]: 327-328). De ahí también que el retorno a la política de clase se haga casi inevitablemente desde la exterioridad y la representación (Alba, 2014; Moscoso, 2016; Pacheco, 2017; Parra, 2017), igual que ocurre con el antirracismo, y que adopte con frecuencia el ropaje paternalista de quien se sabe situado por encima, como tantas veces traiciona el lenguaje (Álvarez y Ouviña, 2017). Son menos frecuentes los análisis que señalan que, centrado en la «clase» o centrado en la «cultura», el discurso de izquierdas tiende a separar el sujeto político (los activistas) del objeto que debe ser interpelado, concienciado u organizado (las mayorías sociales), por lo que en realidad el quid del debate estaría no en lo que la izquierda debe o no hacer sino en la autonomía y el encuentro de los diversos colectivos subalternos en formas de resistencia útiles (Fernández-Savater, 2018; Rodríguez, 2018).

Diversos estudios muestran que la idea de raza ha sido desacreditada y desplazada política y analíticamente en toda Europa, aunque siga siendo de facto un principio organizador de sus sociedades europeas (Johansson, 2017: 4). Posiblemente la islamofobia haya contribuido a ahondar en la confusión respecto a qué son la raza y el racismo y cuál es su función estructural. La dualidad de la islamofobia, al dirigirse a la vez contra un grupo humano y contra una práctica cultural y religiosa - reducida a rasgos monstruosos-, genera algunas aporías. Centrar el debate

nativa, votante de izquierdas o de derechas, tiene también más reticencias a las políticas de no discriminación respecto a las personas de origen inmigrante, que son percibidas como competidoras por los recursos sociales.

14 Rendueles se refiere al Informe Foessa 2014, que da un 29\% de asociacionismo en España frente a un 42,5\% de media europea y muy lejos de los niveles superiores que representan Dinamarca $(91,7 \%)$, Suecia $(82,2 \%)$ y Holanda (79,5\%) (cit. en Lenore, 2016). 
en la cuestión religiosa invisibiliza los demás resortes del racismo y el hecho de que este afecta también a personas no musulmanas o incluso se puede dar entre personas musulmanas. Aunque la islamofobia haya "convertido una religión, el islam, en una raza» (Bayoumi, 2006: 270), se nutre de elementos diversos que van más allá de la pronunciación de la shahada. Por otro lado, poner el foco en la religión da pie a que se consideren islamófobas per se las críticas al islam. En el otro extremo, ignorar o minimizar la dimensión religiosa, como hace una parte del antirracismo, significa crear un sujeto irreal, a la medida de las obsesiones antirreligiosas, y no tener en cuenta que la problematización del islam es en estos momentos el principal mecanismo de producción de alteridad y naturalización de una relación de dominación.

Teniendo en cuenta que la mayor parte de la izquierda no manifiesta posturas concretas ni explícitas sobre la islamofobia, sí pueden señalarse al menos tres posiciones emergentes.

En primer lugar, la existencia de sectores que, desde la izquierda, participan activamente en la estigmatización de los musulmanes ha sido señalada repetidas veces, incluso como uno de los pilares en los que se sustenta la islamofobia. En particular, la islamofobia de izquierdas aparece vinculada a tres ejes: los lineamientos en política internacional, el laicismo y determinadas posturas del feminismo liberal. Con frecuencia, sobre todo en el caso de agentes individuales académicos, intelectuales mediáticos-, la islamofobia forma parte de un desplazamiento ideológico general hacia la derecha y la ultraderecha. Pensemos en los «nuevos filósofos» franceses, de origen maoísta (Achcar, 2016 [2013]: 53-77), o en los exmilitantes trotskistas fundadores del movimiento neocon (Massoumi et al., 2017b: 234). Existen no obstante posicionamientos islamófobos anclados en lógicas de izquierdas.

Las segmentaciones de la izquierda y del movimiento feminista en torno a los distintos "asuntos del velo" en Francia participan tanto de la lógica laica como de la larga tradición dialéctica islamoccidente construida en torno a "la mujer» y su regulación vestimentaria (Göle, 2007 [2005]: 130131; Ramírez, 2014). Si bien la izquierda francesa representa un caso singular en su asunción mayoritaria del consenso social «republicano» (Lévy, 2010), las posiciones de «laicismo excluyente» o de "laicismo incluyente autoritario» que analiza Ángeles Ramírez (2014: 120-125) encuentran correlatos en otros lugares. En España, la problematización del uso del velo en la escuela y sus justificaciones progresistas y laicas (Mijares, 2014) parecen trasladar directamente el debate francés, a pesar de la disparidad de los contextos. Quizás se deba a la influencia de la clase intelectual surgida durante la Transición, de formación francófona y de raíz izquierdista, aunque luego haya evolucionado hacia posturas diversas (Gómez, 2014). En el ámbito anglosajón, tradicionalmente más favorable a la expresión religiosa y cultural, se ha señalado la influencia ejercida por el new atheism y en particular por la obra de Richard Dawkins, cuya caracterización de las religiones como inherentemente opresivas y violentas cimentó el repertorio antiislámico. Un desarrollo de las ideas de Dawkins en la izquierda lo constituye el libro God is not Great de Christopher Hitchens $(2007)^{15}$, antiguo militante del Socialists Workers Party (SWP), que constituye una muestra de la "adaptación de la causa del ateísmo a la islamofobia» (Molyneux, 2008).

\footnotetext{
${ }^{15}$ Traducido al castellano con el título Dios no es bueno (Debate, 2008), aunque el título original realiza un juego de palabras evidente con el takbir musulmán.
} 
Existe una variante del laicismo que considera el islam como particularmente intolerable, bien porque juzga que el cristianismo es constitutivamente más afín a la izquierda, bien porque piensa que la Iglesia, en Occidente al menos, ha sido domeñada por la llustración, lo que no ha ocurrido con el islam. En ese sentido, los postulados de Slavoj Žižek sobre una reactivación de las cuestiones de clase pasan por superar lo que llama «tabúes de la izquierda»: el multiculturalismo, la crítica al eurocentrismo, la relativización de los valores occidentales, etc. (Žižek, 2016: 23 y ss.). El filósofo esloveno considera que el Refugees welcome y otras frivolidades «buenistas» constituyen una instrumentalización de la izquierda por el islam político y que la pérdida de territorio en favor de la ultraderecha es una consecuencia de ese candor que va a contrapelo del sentir de gran parte de la población europea. Žižek separa a duras penas lo que llama «islamofascismo» del islam a secas, ya que, como muchos otros autores, parece considerar que el «mal islam» no es más que el desarrollo hasta las últimas consecuencias de una religión esencialmente machista y violenta: «Los musulmanes son en Occidente una minoría explotada y apenas tolerada (sí, pero los negros africanos también lo son, incluso más, y sin embargo no se dedican a lanzar bombas y a matar)" (Žižek, 2015: 14). Otros autores consideran que la izquierda laica no puede establecer afinidades con el islam equivalentes a las que se han dado con otros movimientos religiosos como la Iglesia de base o la teología de la liberación, debido no solo a que el islam no ha tenido su llustración sino también a que, al contrario que el cristianismo, no posee una «afinidad electiva» con el socialismo (Achcar, 2016 [2013]: 38-47) ${ }^{16}$.

En cuanto a los efectos de la política internacional, las guerras contra Iraq (1990 y 2003) y otras intervenciones estadounidenses en Oriente Medio, si bien suscitaron una amplia contestación antibélica, también contaron con defensores de la "acción humanitaria» y la necesidad de provocar cambios de régimen en favor de la democratización y los derechos humanos. La guerra de 1990-1991 encontró entre sus principales defensores a un sector que era, en los años noventa, hegemónico en la izquierda radical alemana: el movimiento antideutsche («antialemán»). Esta corriente articulaba el comunismo con un acusado apoyo militante a Israel, lo que resultaba en posiciones atípicas. Así, durante la guerra del Golfo, tomaron -y lograron que otros sectores de la izquierda alemana los secundaran- posiciones favorables a la intervención estadounidense, que caracterizaban la oposición a la guerra y la solidaridad con el mundo árabe y con Palestina como filonazi y antisemita (Nadi, 2014a y 2014b) ${ }^{17}$. En el Reino Unido, la ocupación de Afganistán y la guerra de 2003 dieron pie a la amplia coalición Stop the War, construida sobre la alianza entre el ala izquierda del laborismo, el SWP y la Muslim Association of Britain (MAB). Un sector de la izquierda reaccionó entonces contra lo que consideraba una relación contra natura y un abandono de los valores democráticos y progresistas en favor de un reaccionarismo antisemita y sexista que a su juicio representaban tanto las organizaciones musulmanas en la coalición como los regímenes contra los que se dirigía la acción militar. Una consecuencia directa de esta oposición fue el Manifiesto de Euston, que Ilamaba la atención a la izquierda por sus derivas islamófilas,

\footnotetext{
${ }^{16}$ Achcar entiende el concepto weberiano de afinidad electiva como una "propensión» de cada una de las religiones (cristianismo e islam) a tener puntos comunes con el socialismo. Considera que el retorno del cristianismo a su origen constituye un "utopismo comunitarista», mientras que lo propio en el caso del islam solo conduce al «utopismo reaccionario» de los islamistas (Achcar, 2016 [2013]: ibíd.: 43).

${ }^{17}$ La línea antideutsche ha declinado desde entonces en la izquierda radical alemana, debido en gran medida a sus lineamientos islamófobos y proestadounidenses. Sin embargo, sigue siendo influyente en círculos académicos e intelectuales y en sectores de formaciones como Die Linke o Die Grünen.
} 
propalestinas y similares. Uno de sus promotores fue el teórico marxista Norman Geras (Geras et al., 2006), y uno de sus firmantes el arriba nombrado Christopher Hitchens. También el apoyo sin fisuras al gobierno sirio que ha mostrado una parte de la izquierda española en las circunstancias actuales, sobre la base del supuesto laicismo de aquel, ha sido interpretado como un factor alimentado por las mismas visiones esencialistas del islam ( $y$ del islam político) que forman parte del repertorio islamófobo (Karvala et al., 2016: 12; Hayek, 2017).

La segunda posición sería la de un sector de la izquierda europea, encabezada especialmente por el SWP británico, que en la dicotomía raza/clase o cultura/clase esbozada más arriba trata de establecer alianzas con los colectivos racializados desde la posición clásica de la centralidad de clase. En todo caso, se adhiere a una interseccionalidad estratégica que considera que la clase obrera europea realmente existente es «cada vez más diversa en sus colores, orígenes nacionales y creencias religiosas» (Callinicos, 2004). Esta posición deriva en gran medida de la búsqueda de puntos de encuentro entre la izquierda y el islam político expresada por Chris Harman (1994) en The Prophet and the Proletariat, y está fundada en dos aspectos. El primero, la constatación del papel de la islamofobia como principal apoyo ideológico del imperialismo, similar al que tuvo el racismo clásico en los siglos XVIII y XIX, lo que obliga a una comprensión teórica del hecho religioso para adoptar una orientación política adecuada. El segundo es un análisis de la religión no en términos esencialistas ni mecanicistas sino como fenómeno susceptible de una selección, interpretación y adaptación casi infinitas, por lo que lo decisivo no es la doctrina sino la base social en una situación social específica (Molyneux, 2008). El SWP se centra por tanto en deshacer las reticencias laicas de la izquierda recordando que para el marxismo y sus tradiciones revolucionarias fundacionales la religión es "más que opio ${ }^{18}$, lo que tiene el efecto a su vez de centrar el análisis de la islamofobia en su aspecto religioso, aunque no ignore los demás. También toma de la tradición comunista su vocación de partido de vanguardia, cuya responsabilidad como "tribunos del pueblo» le obliga a proporcionar a los musulmanes un vínculo colectivo anticapitalista, que a la larga pueda sustituir a la religión (Callinicos, 2004). Las posiciones del SWP tienen un correlato en otras organizaciones pertenecientes a la Corriente Socialismo Internacional, como En Lucha en el caso español, o afines a ella en el análisis, como Que Faire ?, publicación y corriente del NPA francés (Acqua, 2010) o Corriente Roja, nuevamente en España. La obra colectiva Combatir la islamofobia, dirigida por David Karvala (2016) se sitúa en esta línea y también considero más o menos análoga Islamofobia, de Santiago Alba (2015). Hubo un áspero debate entre el SWP británico y un sector de la izquierda radical francesa en torno a la compatibilidad del islam y la tradición revolucionaria, que incluyó un cruce de acusaciones de complicidad con la islamofobia o con el islamismo. Los distintos modelos de gestión de la diferencia en ambos países parecen reflejarse en sus izquierdas, incluso en aquellas que pertenecen a tradiciones muy cercanas (Cassen, 2004, Callinicos; 2004). Igual que el modelo del SWP es defendido en Francia por un sector del NPA, la Alliance for Workers' Liberty (AWL), también trotskista, representaría las posiciones laicas y anticulturalistas en el Reino Unido.

\footnotetext{
${ }^{18}$ Se trata de un guiño a la famosa frase «la religión es el opio del pueblo», que falsea la cita original de Marx: "La miseria religiosa es, al mismo tiempo, la expresión de la miseria real y la protesta contra ella. La religión es el sollozo de la criatura oprimida, es el significado real del mundo sin corazón, así como es el espíritu de una época privada de espíritu. Es el opio del pueblo» (Marx, 2010 [1844]: 7-8).
} 
Por último, la tercera posición sería la de la crítica descolonial. El Parti des Indigènes de la République (PIR), creado en 2005, articula en Francia una potente experiencia de autoorganización de colectivos racializados, reapropiándose de la categoría colonial de indígenas igual que hicieron décadas atrás los blacks británicos. EI PIR se vincula a la línea de pensamiento descolonial (o decolonial), que incide en el carácter estructural e institucional del racismo, en la sobredeterminación de la "matriz de poder» colonial sobre las múltiples jerarquías imbricadas (o heterarquía) que constituyen el capitalismo - raciales, sexuales, de género, de clase, espirituales, lingüísticas, pedagógicas, epistemológicas, etc. - y critica el pretendido universalismo del pensamiento europeo. Aboga por la autonomía estratégica de los sujetos subalternos, cuya diversidad de resistencias se analiza en términos de pensamiento fronterizo o transmodernidad, entre otros. Desde esa perspectiva, el pensamiento descolonial no tiene contradicción con las resistencias formuladas desde marcos como el del islam o el islamismo político. El PIR, como el resto del pensamiento descolonial, dirige buena parte de sus críticas contra la izquierda «eurocéntrica» de la que procede (Grosfoguel, 2009; Khiari, 2012 [2011]), precisamente porque la considera "aliada indispensable de los indígenas y, a la vez, su adversario primero», en expresión de Houria Bouteldja (cit. en Monzat, 2016). A su vez, en el crispado debate francés, el PIR ha recibido desde algunos sectores de la izquierda acusaciones que van desde el uso torticero de la cuestión colonial (Bensaïd et al., 2005) hasta el flirteo con el islamismo, el sexismo y la homofobia (Halimi, 2016b). En España, la experiencia del PIR se refleja en una incipiente experiencia autoorganizativa de personas racializadas que saltó a la escena pública en la manifestación contra el racismo institucional del 12 de noviembre de 2017, pero que llevaba ya entonces más de un año visibilizándose en actividades, medios digitales y redes sociales. Como en el caso del PIR, gran parte de la carga crítica se dirige contra la izquierda (Garcés, 2016, 2017) y contra el feminismo "blanco» (Adlbi, 2016), en unos términos que hacen pensar en la noción de esencialismo estratégico (Keucheyan, 2013 [2010]): 276-277) como modo de forjarse una identidad y un lugar en el campo político antes de pasar a las afinidades estratégicas ${ }^{19}$. En relación con éstas, el espacio político descolonial, al menos en el caso español, parece adecuarse mejor al ámbito difuso e interseccional de los movimientos y los centros sociales que al de las organizaciones políticas, a pesar de que, en la práctica, el racismo haya sido hasta el momento una preocupación marginal también en esos espacios (Johansson, 2017) ${ }^{20}$.

\footnotetext{
${ }^{19}$ Puede consultarse en este sentido el largo intercambio entre Helios F. Garcés y Santiago Alba Rico desde las páginas de, respectivamente, El Salto y Cuatro Poder, con más aspereza que diferencia. Los artículos que abren la serie de ocho textos son Garcés, 2017 y Alba Rico, 2017.

${ }^{20}$ Sandra Johansson señala que el racismo rara vez es objeto de debate público en España, en parte porque la idea de raza no se considera una cuestión relevante ni en la política ni en la investigación. Constata que aunque existe una abundante literatura sobre organizaciones políticas y movimientos sociales en España, parte de la cual explora aspectos interseccionales, no se presta demasiada atención al racismo. Cita un estudio específico sobre interseccionalidad en el 15-M, que después de reconocer el vínculo fundacional entre la misma idea de interseccionalidad y la visibilización de la desigualdad de raza, considera que esta última dimensión no es dominante en el contexto español, por lo que no la trata (Cruells López y Ruiz García, 2014: 3).
} 


\section{Conclusiones}

La relación de la izquierda con la islamofobia es difícilmente generalizable, por la propia diversidad interna de las posiciones políticas que se reconocen o son comúnmente reconocidas con el significante izquierda. He optado aquí por no adentrarme en el terreno complejo y contradictorio de los significados y referentes de la llamada izquierda, porque lo contrario habría resultado paralizante. Pero soy consciente de que en este punto no solo es obligada una mayor definición, sino también de que, posiblemente, en la ruptura con las taxonomías que se imponen a la intuición o al sentido común se encuentren algunas de las claves explicativas de las relaciones entre islamofobia y política. Como las teleseries, emplazo en todo caso a un continuará.

Provisionalmente y en términos generales, puede decirse que la (re)producción de la islamofobia corresponde fundamentalmente a otros extremos del arco político y a la institucionalidad, aunque algunos sectores reconocidos como parte de la izquierda participen de ella. El antirracismo en general y la islamofobia en particular no parecen ocupar un lugar relevante en los discursos de izquierdas, aunque por otra parte el antirracismo se vincula más a determinados sectores de izquierdas que a cualquier otro actor político. El antirracismo tiene cierto valor como referente ideológico en el conjunto de la izquierda, pero por un lado la islamofobia no es necesariamente percibida como una forma de racismo y por otro la concreción de ese antirracismo depende de su performatividad en el campo político, que hasta el momento ha sido escasa.

La razón de ello no parece deberse tanto a discusiones teóricas sino a la desorientación producida por la descomposición general de la antigua base social de la izquierda y a la pérdida de relevancia de esta, por una parte. Y por otra, a la propia homogeneidad interna de los ámbitos militantes, que por una pura cuestión de afinidades vitales deja fuera a (o no es atractiva para) sectores sociales minorizados y subalternos. Con los que, por otra parte, algunas tradiciones de la izquierda tienden a establecer una relación maestro-discípulo que parece ir a la contra de las formas de contestación social que se han dado en los últimos años. Los movimientos ciudadanos que han recorrido el Mediterráneo a lo largo de la década invitan a creer que las recomposiciones de la contestación, de haberlas, surgirán más de la autonomía de los sujetos que de la acción voluntarista de las vanguardias.

Uno de los aspectos más difíciles y a la vez estimulantes de la investigación es, precisamente, la vertiginosa mutación del terreno. La inestabilidad social, la llegada al poder de formaciones hasta ahora marginales o inexistentes o la constatación del papel central que juega el racismo y sus avatares (securitarios, laicistas, etc.) en las reconfiguraciones políticas ${ }^{21}$ permiten vislumbrar algunos cambios en las relaciones de ese espacio político confuso y contradictorio que llamamos izquierda con el igualmente complejo fenómeno de la islamofobia. En España, los últimos dos años escasos han sido testigos de la aparición de un nuevo sujeto político racializado, formado en gran medida - aunque no exclusivamente- por hijos e hijas de la inmigración, que ha tenido ya efectos en la configuración de las luchas antirracistas y en la consideración que dichas luchas tienen en espacios de contestación más amplios. Este actor emergente nace con el andamiaje

\footnotetext{
21 No obstante, como puntualizan Hajjat y Mohammed (2016: 132-133), la rentabilidad electoral del discurso islamófobo es una idea por el momento más afirmada que demostrada empíricamente.
} 
teórico descolonial y con el bagaje de sus predecesores en Francia, el Reino Unido y otros países europeos. Huelga decir que el paisaje político español en general ha experimentado mutaciones que hubieran sido inimaginables hace muy pocos años.

Por otra parte, hemos considerado al inicio de este artículo que la islamofobia -como el racismo en general- tiene una genealogía occidental, es decir, que su foco emisor como ideología imperial son los Estados Unidos y su terreno principal como dispositivo de disciplinamiento de poblaciones es Europa. Siendo así, cabe preguntarse por las implicaciones que pueda tener la consolidación de un capitalismo no occidental (cuyos polos de desplazan, por ejemplo, hacia China) y en qué medida las actuales configuraciones del racismo, que se ejerce sobre los otros históricos de Europa, constituyen una especie de hábitus reflejo de un contexto social ya en declive.

\section{Bibliografía}

ACHCAR, Gilbert (2016 [2013]): Marxismo, orientalismo, cosmopolitismo, Barcelona, Bellaterra. ADLBI SIBAI, Sirin (2016): La cárcel del feminismo. Hacia un pensamiento islámico decolonial, México, Akal.

ACQUA, Giulia (2010): «Marxisme et religion», Que faire ?, marzo-abril de 2010, pp. 23-28.

AGAMBEN, Giorgio (2003 [1995]): Homo sacer. El poder soberano y la nuda vida, Valencia, PreTextos.

- (2004 [2003]): Estado de excepción. Homo sacer, II, I, Buenos Aires, Adriana Hidalgo.

ALBA RICO, Santiago (2014): "El lío de Podemos y los tres elitismos», Cuarto Poder, 4/10/2014, disponible en: https://www.cuartopoder.es/ideas/opinion/2014/10/04/el-lio-de-podemos-y-lostres-elitismos/ [consulta: 12/3/2018].

- (2015): Islamofobia. Nosotros, los otros, el miedo, Barcelona, Icaria.

- (2017): «Racismo y antirracismo, ¿en qué jaula estamos?», Cuarto Poder, 20/5/2017, disponible en: $\quad$ https://www.cuartopoder.es/ideas/2017/03/25/racismo-y-antirracismo-en-que-jaulaestamos/ [consulta: 12/3/2018].

ÁLVAREZ, Antonella y OUVIÑA, Hernán (2017): «Entrevista a Brais Fernández: "Entre la movilización y la disputa del poder deberíamos organizar a las clases subalternas"», Viento Sur, 20/2/2017, disponible en: http://vientosur.info/spip.php?article12236 [consulta: 12/3/2018].

BAUMAN, Zygmunt (1998 [1977]): Modernidad y Holocausto, Madrid, Sequitur.

BAYOUMI, Moustafa (2006) «Racing Religion», The New Centennial Review, vol. 6, n.으 2, pp. 267293.

BENSAÏD, Daniel, JOHSUA, Samuel y VACHETTA, Roseline (2005): "Quand la raison s'affole», Libération, 21/3/2005, disponible en: http://www.liberation.fr/tribune/2005/03/21/quand-laraison-s-affole 513708 [consulta: 12/3/2018]. 
BERNABÉ, Daniel (2018): La trampa de la diversidad. Cómo el neoliberalismo fragmentó la identidad de la clase trabajadora, Madrid, Akal.

BOURDIEU, Pierre y WACQUANT, Loïc (1995): Respuestas. Por una antropología reflexiva, México, Grijalbo.

BRAH, Avtar (2011 [1996]): Cartografías de la diáspora: identidades en cuestión, Madrid, Traficantes de Sueños.

CALLINICOS, George (2004): "The European Radical Left Tested Electorally», International Viewpoint, 9/12/2004, disponible en: http://www.internationalviewpoint.org/spip.php?article10[consulta: 12/3/2018].

CARMONA, Pablo, GARCÍA, Beatriz y SÁNCHEZ, Almudena (2012): Spanish Neocon. La revuelta neoconservadora en la derecha española, Madrid, Traficantes de Sueños.

CARRETERO, Andrés (2017) "César Rendueles, filósofo y escritor: "Deberíamos recordar que todo esto empezó con una crisis de acumulación capitalista"», CTXT, 29/10/2017, disponible en: http://ctxt.es/es/20171025/Politica/15860/entrevista-Rendueles-economia-politica-sistema.htm [consulta: 12/3/2018].

CASSEN, Bernard (2004): "Ces altermondialistes en perte de repères», Politis, 20/1/2004, disponible en: https://local.attac.org/13/aix/spip.php?article406 [consulta: 12/3/2018].

CASALS MESEGUER, Xavier (2017): "La evolución de la ultraderecha en España: claves históricas y territoriales», Análisis del Real Instituto Elcano, 59/2017, pp. 1-9.

CRUELLS LÓPEZ, Marta, y RUIZ GARCÍA, Sonia (2014): «Political Intersectionality within the Spanish Indignados Social Movement», en WOEHRLE, Lynne M. (ed.), Intersectionality and Social Change. Research in Social Movements, Conflicts and Change, vol. 37, Bingley, Emerald, pp. 3-25.

DANCYGIER, Rafaela M. (2017): Dilemmas of Inclusion. Muslims in European Politics, Princeton, Princeton University Press.

- (2018): "Muslim Voters and the European Left. When Inclusion Leads to Populism», Foreign Affairs, 6/2/2018, disponible en: https://www.foreignaffairs.com/articles/europe/2018-0206/muslim-voters-and-european-left [consulta: 12/3/2018].

EUROPA PRESS (2018): «Intentan recaudar fondos para repatriar el cadáver de Mame Mbaye a Senegal», Diario de Avisos, 16/3/2018, disponible en: https://diariodeavisos.elespanol.com/2018/03/intentan-recaudar-fondos-para-repatriar-el-

cadaver-de-mame-mbaye-a-senegal/ [consulta: 17/3/2018].

FEDERICI, Silvia (2010 [2004]): Calibán y la bruja. Mujeres, cuerpo y acumulación originaria, Madrid: Traficantes de Sueños.

FERNÁNDEZ-SAVATER, Amador (2018): «Política de clase como política del encuentro», ElDiario.es, 8/2/2018, disponible en: https://www.eldiario.es/interferencias/clase obreraCornelius Castoriadis 6 738486148.html [consulta: 12/3/2018].

FINKELSTEIN, Norman (2002 [2000]): La industria del Holocausto. Reflexiones sobre la explotación del sufrimiento judío, Tres Cantos, Siglo XXI.

FRAENKEL, Ernst (1941): The Dual State. A Contribution to the Theory of Dictatorship, Nueva York, Oxford University Press.

GARCÉS, Helios F. (2016): «La "nueva izquierda" ante el espejo racializado», Diagonal, 21/5/2016, disponible en: https://www.diagonalperiodico.net/global/30294-la-nueva-izquierda-ante-espejoracializado.html [consulta: 12/3/2018].

- (2017): "La izquierda y el racismo: cegueras y reacciones», El Salto, 17/3/2017, disponible en: https://saltamos.net/la-izquierda-y-el-racismo-cegueras-y-reacciones/ [consulta: 12/3/2018].

GARZÓN, Alberto (2016): «iDigamos adiós a la izquierda pija!», ElDiario.es, 12/11/2016, disponible en: $\quad$ https://www.eldiario.es/tribunaabierta/Digamos-adios-izquierda-pija 6 579602050.html [consulta: $12 / 3 / 2018$ ]. 
GERAS, Norman et al. (2006): The Euston Manifesto. For a Renewal of Progressive Politics, disponible en: http://eustonmanifesto.org/the-euston-manifesto/ [consulta: 12/3/2018].

GIL-BENUMEYA, Daniel (2016): «No se integran ni después de muertos», Webis/am, 17/03/2016, disponible en: https://www.webislam.com/articulos/109429no_se_integran_ni_despues_de_muertos.html [consulta: 30/5/2018].

GÖLE, Nilüfer (2007 [2005]): Extramodernidades. El islam y Europa, Barcelona, Bellaterra.

GÓMEZ GARCÍA, Luz (2014): «Dar la voz para quitarla. Islamofobia y musulmanes esclarecidos en España», en RAMÍREZ, Ángeles (ed.), La alteridad imaginada: el pánico moral y la construcción de lo musulmán en España y Francia, Barcelona, Bellaterra, pp. 45-77.

GONZÁLEZ ENRÍQUEZ, Carmen (2017): "La excepción española: el fracaso de los grupos de derecha populista pese al paro, la desigualdad y la inmigración", Documento de Trabajo, 7/2017, Real Instituto Elcano, pp. 1-41.

GROSFOGUEL, Ramón (2009): «Izquierdas e Izquierdas Otras: entre el proyecto de la izquierda eurocéntrica y el proyecto transmoderno de la nuevas izquierdas descoloniales», Tabula Rasa, n.ㅇ 11, julio-diciembre de 2009, disponible en: http://www.scielo.org.co/scielo.php?pid=S179424892009000200001\&script=sci arttext\&tlng=en [consulta: 12/3/2018].

HAJJAT, Abdellali y MOHAMMED, Marwan (2016): Islamophobie. Comment les élites françaises fabriquent le "problème musulman ", París, La Découverte.

HALIMI, Serge (2016a): “¿Porqué [sic] los pobres votan a la derecha?», Viento Sur, 27/07/2016, disponible en: http://vientosur.info/spip.php?article11554 [consulta: 12/3/2018].

- (2016b): «Ahmadinejad, mon héros», Le Monde Diplomatique, agosto de 2016, p. 26, disponible en: https://www.monde-diplomatique.fr/2016/08/HALIMI/56087 [consulta: 12/3/2018].

HALLIDAY, Fred (1999): ""Islamophobia" reconsidered», Ethnic and racial Studies, 22: 5, pp. 892902.

HARMAN, Chris (1994): "The Prophet and the Proletariat», International Socialism, otoño de 1994, disponible en: https://www.marxists.org/archive/harman/1994/xx/islam.htm [consulta: 12/3/2018].

HARVEY, David (2004 [2003]): El nuevo imperialismo, Tres Cantos, Akal. HAYEK, Caroline (2017): "Comment Assad est devenu " le blanc " de l'extrême-droite occidentale», L'Orient/Le Jour, 15/8/2017, disponible en: https://www.lorientlejour.com/article/1067327/comment-assad-est-devenu-le-blanc-delextreme-droite-occidentale.html [consulta: 12/3/2018].

HERNÁNDEZ, Esteban (2017a): «¿Qué hacemos con los nuestros? El gran dilema de la izquierda», El Confidencial, 22/6/2017, disponible en: https://blogs.elconfidencial.com/espana/postpolitica/2017-06-22/que-hacemos-nuestros-grandilema-izquierda 1403884/ [consulta: 12/3/2018].

- (2017b): «Entrevista con Alberto Garzón: "Los votantes de la izquierda son las clases medias ilustradas, no los obreros"», El Confidencial, 21/10/2017, disponible en: https://blogs.elconfidencial.com/espana/postpolitica/2017-06-13/constemocion-mocionpodemos-texto-apoyo-telegram-ridiculizar 1398190/ [consulta: 12/3/2018].

JOHANSSON, Sandra (2017): The Involuntary Racist. A Study on White Racism Evasiveness amongst Social Movements Activists in Madrid, Spain (TFM), Linköping, Linköping University.

JONES, Owen (2012 [2011]): Chavs. La demonización de la clase obrera, Madrid, Capitán Swing. JUHEM, Pierre (1998): SOS Racisme, histoire d'une mobilisation "apolitique», Nanterre, Université de Nanterre. 
KAPITAN, Tomis (1997): "The Israeli-Palestinian Conflict: Its History, and Some Philosophical Questions it Raises», en KAPITAN, Tomis (ed.), Philosophical Perspectives on the Israeli-Palestinian Conflict, Nueva York, M. E. Sharpe, pp. 3-45.

KARVALA, David (ed.) (2016): Combatir la islamofobia: una guía antirracista, Barcelona, Icaria.

KEUCHEYAN, Razmig (2013 [2010]): Hemisferio izquierda. Un mapa de los nuevos pensamientos críticos, Tres Cantos, Siglo XXI.

KUMAR, Deepa (2017): "Islamophobia and Empire: An Intermestic Approach to the Study of AntiMuslim Racism", en MASSOUMI, Narzanin, MILLS, Tom, y MILLER, David (eds.), What is Islamophobia? Racism, Social Movements and the State, Londres, Pluto Press, pp. 49-73.

KUNDNANI, Arun (2017): "Islamophobia as Ideology of US Empire», en MASSOUMI, Narzanin, MILLS, Tom, y MILLER, David (eds.), What is Islamophobia? Racism, Social Movements and the State, Londres, Pluto Press, pp. 35-48.

LA CONTRAPARTE (2018): ¿El regreso de la ultraderecha? Racismo y fascismo en la era Trump (programa de radio), disponible en: https://www.ivoox.com/de/contraparte-14-el-regreso-ultraaudios-mp3 rf 24102022 1.html [consulta: 12/3/2018].

LENORE, Víctor (2016): «¿Existen movimientos sociales en España?», La Circular, 7/6/2016, disponible en: http://lacircular.info/existen-movimientos-sociales-en-espana/ [consulta: $12 / 3 / 2018]$.

- (2018): "La izquierda española vive en una burbuja (sus mejores pensadores ya no lo niegan)», El Confidencial, 21/1/2018, disponible en. https://www.elconfidencial.com/cultura/2018-0121/izquierda-espanola-burbuja-pensamiento 1508355/[consulta: 12/3/2018].

LÉVY, Laurent (2010): La " gauche », les Noirs et les Arabes, París, La Fabrique.

LÓPEZ BARGADOS, Alberto (2014): "Autos de fe en un mundo de incrédulos: etnografiando la construcción del "terror islámico" en Cataluña», en RAMÍREZ, Ángeles (ed.), La alteridad imaginada: el pánico moral y la construcción de lo musulmán en España y Francia, Barcelona, Bellaterra, 2014, pp. 23-44.

LÓPEZ GARCÍA, Bernabé (2002): «El islam y la integración de la inmigración social», Cuadernos de Trabajo Social, vol. 15, págs. 129-143.

LORENC VALCARCE, Federico (2005): «La sociología de los problemas públicos. Una perspectiva crítica para el estudio de las relaciones entre la sociedad y la política», Nómadas. Revista Crítica de Ciencias Sociales y Jurídicas, vol. 12, n. 2, pp.141-150.

MARX, Karl (2010 [1844]), Crítica de la filosofía del Estado de Hegel, Madrid: Biblioteca Nueva.

MASSOUMI, Narzanin, MILLS, Tom, y MILLER, David (2017a): «Islamophobia, Social Movements and the State: For a Movement-Centered Approach", en MASSOUMI, Narzanin, MILLS, Tom, y MILLER, David (eds.), What is Islamophobia? Racism, Social Movements and the State, Londres, Pluto Press, pp.3-32.

- (2017b): "Liberal and Left Movements and the Rise of Islamophobia», en MASSOUMI, Narzanin, MILLS, Tom, y MILLER, David (eds.), What is Islamophobia? Racism, Social Movements and the State, Londres, Pluto Press, pp. 234-267.

MIJARES, Laura (2014): «El efecto Persépolis: procesos de domesticación y marginación de alumnas musulmanas en los centros educativos», en RAMíREZ, Ángeles (ed.), La alteridad imaginada: el pánico moral y la construcción de lo musulmán en España y Francia, Barcelona, Bellaterra, pp. 189-217.

MOLYNEUX, John (2008): «More than Opium: Marxism and Religion», International Socialism, n.은 119, 24/6/2008, disponible en: http://isj.org.uk/more-than-opium-marxism-and-religion/ [consulta: 12/3/2018]. 
MONZAT, "La gauche peut-elle dire " nous" avec Houria Bouteldja ?», Contretemps, 22/4/2016, disponible en: http://www.contretemps.eu/la-gauche-peut-elle-dire-nous-avec-houria-bouteldja/ [consulta: $12 / 3 / 2018$ ].

MOSCOSO, María Fernanda (2016): "Contra la izquierda», Ideas, 19/7/2016, disponible en: http://www.planv.com.ec/ideas/ideas/contra-la-izquierda [consulta: 12/3/2018].

MOUFFE, Chantal (2007): En torno a lo político, Buenos Aires, Siglo XXI.

NADI, Selim (2014): "Antideutsch: sionisme, antifascisme et antinationalisme dans la gauche radicale allemande», Période, marzo de 2014, disponible en: http://revueperiode.net/antideutschsionisme-antifascisme-et-antinationalisme-dans-la-gauche-radicale-allemande/\#identifier 26197 [consulta: 12/7/2016].

- (2014b): "Nation, race et impérialisme dans la gauche allemande depuis la réunification", Période, junio de 2014, disponible en: http://revueperiode.net/nation-race-et-imperialisme-dansla-gauche-allemande-depuis-la-reunification/[consulta: 12/7/2016].

PACHECO, Anna (2017): «¿Precarios todos? Los hijos de la clase obrera tienen su propio techo de cristal», Playground, 28/12/2017, disponible en: https://www.playgroundmag.net/now/hijosclase-obrera-techo-cristal- 25054610.html [consulta: 12/3/2018].

PARRA, Raúl (2017): «Frente al fetichismo identitario de la vieja y la nueva izquierda: la "política de la inmanencia" como alternativa», Viento Sur, 15/6/2017, disponible en: http://vientosur.info/spip.php?article12703 [consulta: 12/3/2018].

PITTI, Laure (2004): "Les luttes centrales des O.S. immigrés», Plein droit, n.o 63, pp. 43-47, disponible en: https://www.cairn.info/revue-plein-droit-2004-4-page-43.htm [consulta: 12/3/2018], DOI : https://doi.org/10.3917/pld.063.0043

RAMÍREZ, Ángeles (2014): «Segmentaciones feministas en torno al pañuelo musulmán: feminismos, islam e izquierda en Francia», en RAMÍREZ, Ángeles (ed.), La alteridad imaginada: el pánico moral y la construcción de lo musulmán en España y Francia, Barcelona, Bellaterra, pp. 99139.

REA, Andrea (2006): "La europeización de la política migratoria y la transformación de la otredad», Revista Española de Investigaciones Sociológicas, № 116, pp. 157-183.

REGUERA, Marcos (2017): "Alt Right: radiografía de la extrema derecha del futuro», CTXT, 22/2/2017, disponible en: http://ctxt.es/es/20170222/Politica/11228/Movimiento-Alt-RightEEUU-Ultraderecha-Marcos-Reguera.htm [consulta: 12/3/2018].

Río, Eugenio del (2012): De la indignación de ayer a la de hoy. Transformaciones ideológicas en la izquierda alternativa en el último medio siglo en Europa occidental, Madrid, Talasa.

RODRÍGUEZ, Emmanuel (2018): "Cuando el problema es la izquierda», CTXT, 7/2/2018, disponible en: $\quad$ https://ctxt.es/es/20180207/Firmas/17654/izquierda-movimiento-obrero-emmanuelrodriguez-psoe-pce.htm [consulta: 12/3/2018].

ROMERO, Ricardo [Nega] y TIRADO, Arantxa (2016): La clase obrera no va al paraíso. Crónica de una desaparición forzada, Tres Cantos, Akal.

SAID, Edward W. (1990 [1978]): Orientalismo, Madrid, Libertarias.

SUÁREZ-NAVAZ, Liliana et al. (2007): Las luchas de los sin papeles y la extensión de la ciudadanía. Perspectivas críticas desde Europa y Estados Unidos, Madrid: Traficantes de Sueños.

TAMAS, Gáspar Miklós (2000): "On Post-Fascism. The Degradation of Universal Citishenship», Boston Review, 1/6/2000, disponible en: https://bostonreview.net/world/g-m-tam\%C3\%A1s-postfascism [consulta: 28/2/2018]. 
- (2015): "Gáspar Miklós Tamás: "This is Postascism"», Arbetet Global, 26/9/2015, disponible en: http://arbetet.se/global/2015/09/26/gaspar-miklos-tamas-this-is-post-fascism/ [consulta: 28/2/2018].

TRAVERSO, Enzo (2015): "La transformación "postfascista" arriesga con dinamitar el marco político», Viento Sur, disponible en: http://vientosur.info/spip.php?article10793 [consulta: 28/2/2018].

- (2016): The End of Jewish Modernity, Londres, Pluto Press.

- (2017): «Trump's Savage Capitalism: The Nightmare is Real», World Policy Journal, 34 (1): pp. 13-17.

TYRER, David (2013): The Politics of Islamophobia. Race, Power and Fantasy, Londres, Pluto Press. ŽIŽEK, Slavoj (2015): Islam y modernidad. Reflexiones blasfemas, Barcelona, Herder.

- (2016): La nueva lucha de clases. Los refugiados y el terror, Barcelona, Anagrama. 